\title{
Hydrophobic interactions and chemical reactivity
}

\author{
Sijbren Otto $* a$ and Jan B. F. N. Engberts $* b$ \\ a Department of Chemistry, University of Cambridge, Lensfield Road, Cambridge, \\ UKCB2 1EW.E-mail: so230@cam.ac.uk; Fax: ++44 (0)1223-336017; \\ Tel: ++44 (0) 1223336317 \\ ${ }^{b}$ Physical Organic Chemistry Unit, Stratingh Institute, University of Groningen, Nijenborgh 4, \\ 9747 AG Groningen, The Netherlands.E-mail: j.b.f.n.engberts@chem.rug.nl; \\ Fax: + +31 (0)50-3634296; Tel: + +31(0)50 3634242
}

Received 21st May 2003

First published as an Advance Article on the web 17th July 2003

This perspective describes how kinetic studies of organic reactions can be used to increase our understanding of hydrophobic interactions. In turn, our understanding of hydrophobic interactions can be used as a tool to influence chemical reactions.

\section{Introduction}

Hydrophobic interactions (HI) between apolar molecules or apolar parts of molecules in water have been studied since the last part of the nineteenth century. These interactions are of paramount importance in chemistry. ${ }^{1}$ Aggregation of phospholipids and other lipid components in biological cell membranes is driven by $\mathrm{HI}$ and $\mathrm{HI}$ also play a crucial role in protein folding and often in enzyme-substrate interactions. There are, however, numerous other processes in aqueous solution in various chemical disciplines, which depend strongly on HI.

HI are different from all other noncovalent interactions in the liquid phase in the sense that they do not primarily depend on direct attractive intermolecular interactions between the species that are perceived to interact but are rather driven by the tendency of water molecules to retain their own water-water hydrogen-bond interactions as much as possible, leading to a tendency to arrange nonpolar entities such that the contact surface area between these and water is minimised.

The precise mechanism of HI has been under debate for many decades and still all details are not well understood. Particularly the thermodynamics of dissolution of apolar molecules in water and of HI have been discussed extensively ${ }^{2}$ and it is only recently that consistent interpretations have been advanced. ${ }^{3}$ Much of our current insight is derived from fundamental studies on the transfer thermodynamics of small nonpolar molecules from the gas phase to water, providing information on the way water molecules arrange themselves around nonpolar entities (i.e. hydrophobic hydration). ${ }^{4}$

At room temperature apolar molecules are warmly received (strongly negative enthalpy of transfer) upon transfer from the gas phase to water, yet the Gibbs energy is strongly positive due
Sijbren Otto received his M.Sc. (1994) and Ph.D. (1998) degrees cum laude from the University of Groningen in the Netherlands, working with Jan Engberts. In 1998 he moved to the United States for a year as a postdoctoral researcher with Steve Regen at Lehigh University. In 1999 he received a Marie Curie Fellowship and moved to the University of Cambridge where he worked for two years with Jeremy Sanders. In 2001 he started as a Royal Society University Research Fellow at the same university. His research interests include organic chemistry in water with particular focus on molecular recognition and catalysis in aqueous solution using dynamic combinatorial chemistry.

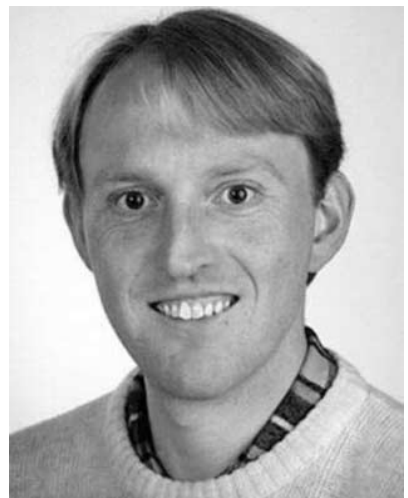

Sijbren Otto
Jan B. F. N. Engberts obtained his M.Sc. (1965) and Ph.D. (1967) degrees cum laude from Groningen University. He received the Unilever Prize in Chemistry in 1961. After a post-doctoral position (1968-1969) at the University of Amsterdam (ESR spectroscopy), he returned to Groningen. He was appointed as Professor of General Chemistry in 1978. Since 1991 he occupies the chair of Physical Organic Chemistry. His research interests are centred around organic chemistry in water. Subprograms include reactivity and catalysis in aqueous reaction media, membrane mimetic chemistry and most recently, the design and study of amphiphilic DNA carrier systems for potential application in gene therapy. His group has published about 425 research papers.

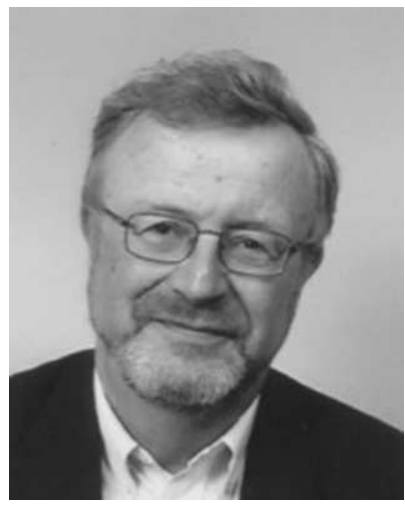

Jan B. F. N. Engberts 
to a dominating large and unfavourable entropic contribution. For many years it was believed that the hydrophobic hydration shells are characterised by a strengthening of water-water hydrogen bonding (more or stronger hydrogen bonds) per volume unit as compared with bulk water. This effect was often described as an increase in "water structure".

Recent rather compelling evidence (neutron scattering, NMR, MD simulations, quantum chemistry, thermodynamics) ${ }^{1}$ suggests that this picture for hydrophobic hydration needs revision. Upon dissolution of relatively small nonpolar molecules at room temperature, the water molecules surrounding the nonpolar surface tend to keep their hydrogen-bonding network largely intact. Since the nonpolar surface cannot donate or accept hydrogen bonds, this leads to a tendency for tangential orientation of the water $\mathrm{O}-\mathrm{H}$ bonds relative to the apolar surface (Fig. 1). This preference for water orientation most likely offers the explanation for the substantial loss of entropy upon transfer of apolar groups or molecules from the gas phase to water.

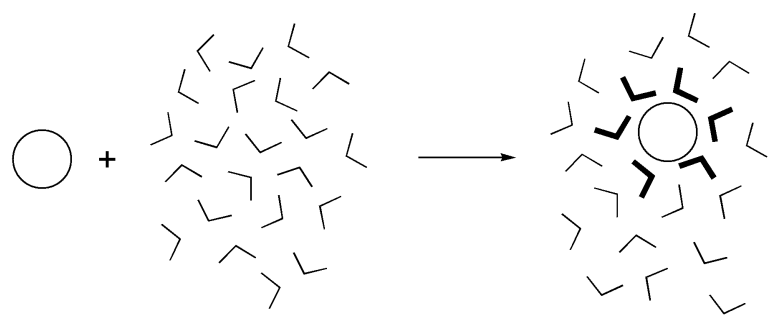

Fig. 1 Water molecules in the hydrophobic hydration shell of small nonpolar molecules at room temperature show a preference for a tangential orientation of their hydrogen bonds with respect to the nonpolar surface.

However, this preference to maintain hydrogen bonds does not appear to be a strong one. Increase in temperature will lead to progressive breaking of hydrogen bonds in the hydrophobic hydration shell, with the transfer of nonpolar molecules from the gas phase to water eventually becoming enthalpically rather than entropically unfavourable. Cosolutes can lead to a similar shift towards a dominating enthalpy term. Similarly, increasing the size and decreasing the curvature of the nonpolar species makes it increasingly difficult to maintain an extensively hydrogen-bonded hydrophobic hydration shell. Hydration of a flat nonpolar surface is inevitably characterised by dangling hydrogen bonds; an arrangement which is even more prevalent in the hydration of nonpolar cavities. For instance, the binding through HI of nonpolar molecules inside the cavity of cyclodextrin receptors is usually enthalpy driven.

HI are driven by the favourable rearrangement of water molecules that can occur upon bringing nonpolar entities together and $\mathrm{HI}$ is essentially a partial reversal of the process of hydrophobic hydration. Where for the formation of the hydrophobic hydration shell water molecules need to be recruited from the bulk solvent, $\mathrm{HI}$ are accompanied by the release of water molecules from the hydrophobic hydration shells back into bulk solution. Therefore the same factors that cause the thermodynamic signature for hydrophobic hydration to vary from entropy-driven to enthalpy-driven (temperature, cosolutes, size, and curvature of the solute) can cause HI to shift from being entropy driven to enthalpy driven.

Upon increasing the concentration of a nonpolar solute to a certain (perhaps $\mathrm{critical}^{5}$ ) concentration, the relatively extensive hydrophobic hydration shells start to overlap destructively, which is accompanied by a release of water molecules from the hydrophobic hydration shell to the bulk aqueous medium. The apolar molecules, which are now in contact with each other, possess a smaller water-accessible surface area than the separate molecules and the release of the waters from their hydrophobic hydration shells provides the driving force for HI. Of course this whole solvent-induced association process is more complex because the two apolar molecules also interact with each other by London dispersion forces. In order to get a more complete overview of HI, the reader is referred to the recent literature. ${ }^{1,4}$

HI can lead to pairwise interactions (short-lived $1: 1$ association, "encounter complexes"), to well-defined host-guest complexes, to the formation of small clusters of molecules ("moving units"), or to the formation of large aggregates ("bulk HI"; micelles, vesicles, etc.). It is clear that HI are associated with a complex interparticle potential that depends on the size ${ }^{3}$ and shapes ${ }^{6}$ of the molecules, on the temperature and pressure, and on the presence of cosolutes.

HI can be studied by a large variety of experimental and computational techniques. In this Perspective, we focus attention on reaction kinetics, i.e. the question how the rates of (organic) reactions in aqueous media are influenced by HI and how HI can be used to enhance reaction rates and improve the stereochemical aspects of a particular reaction.

\section{Use of chemical reactivity to study hydrophobic interactions}

Among the large variety of experimental techniques to study HI, chemical reactivity has a special position. This technique rests on the idea that a chemical reaction in water will be kinetically influenced by the presence of a (low) concentration of a sufficiently hydrophobic and inert cosolute able to interact with the reactants and/or activated complex (AC) of the reaction. First of all, we note that any cosolute that stabilises the water (i.e. lowers the chemical potential of water) will decrease the rate of reaction. ${ }^{7}$ But at low concentrations of cosolute these effects will be small, and reaction rates will be dominated by $\mathrm{HI}$ between the reactants and $\mathrm{AC}$ with the cosolute. The magnitude of the cosolute effect on the rate constant and on the isobaric activation parameters for the reaction will offer information about the HI with the cosolute:

$$
\begin{gathered}
A \stackrel{k_{1}}{\longrightarrow} A C \rightarrow P \\
A \stackrel{\text { cosolute }}{k_{k^{\prime}}} A C \rightarrow P
\end{gathered}
$$

The use of reaction kinetics for studying HI has the advantage that rate constants $\left(k_{1}{ }^{\prime}\right)$ can usually be determined with high precision ( $\pm 2 \%$ is often possible), so that relatively small hydrophobic effects can be investigated. However, the fact that such kinetic medium effects signal differences in the interactions of the cosolute with reactants and $\mathrm{AC}$ makes a quantitative interpretation relatively complex. Nevertheless, the technique can provide insights into the arrangement of nonpolar molecules and the surrounding waters in dilute aqueous solutions at the molecular level. It is particularly suitable for the study of short-lived encounter complexes of molecules with nonpolar regions.

\subsection{Probe reactions}

The kinetic approach has been tested for quite a number of organic $^{8}$ and some inorganic probe reactions. ${ }^{9}$ Perhaps the most systematic and thorough study has been made of the water-catalysed (i.e. $\mathrm{pH}$-independent) hydrolysis of activated esters and amides. Examples of substrates include esters $\mathbf{1}$ (Scheme 1) ${ }^{10}$ In a suitable $\mathrm{pH}$-region ( $\left.\mathrm{pH} c a .2 .0-5.5\right)$, the ratedetermining step (r.d.s.) involves a water-catalysed, nucleophilic attack of water at the carbonyl group, consistent with a substantial kinetic solvent deuterium isotope effect and a strongly negative entropy of activation. Proton inventory studies ${ }^{10 c}$ indicate that three protons are in flight in the $\mathrm{AC}$ whereas a detailed 


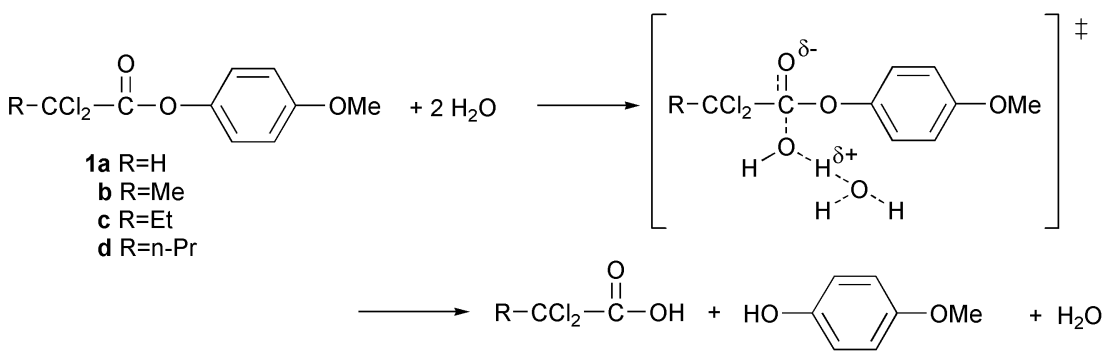

Scheme 1 Examples of ester hydrolysis reactions studied to probe hydrophobic interactions.

MD computer simulation study provides strong evidence of a tunnelling contribution in the proton transfer from the first to the second water molecule. ${ }^{11}$

The role of water in this hydrolytic process is rather peculiar: it is acting as a nucleophile as well as a general base in the r.d.s. and it comprises the reaction medium. For the purpose of studying HI the reaction has definite advantages. For example no buffer is required as soon as the $\mathrm{pH}$ is established by adding a small amount of a strong acid, rates of hydrolysis can be measured conveniently and accurately, and the hydrophobicity of the ester can be varied, both in the acyl (R) as well as in the phenolic part of the molecule.

\subsection{Combined thermodynamic and kinetic analysis}

Already more than a decade ago, it was found that small concentrations of relatively hydrophobic cosolutes (i.e. concentrations at which the cosolute does not self-aggregate) caused rate retardations in the hydrolysis. Using a pseudothermodynamic approach it was shown that initial state (IS) stabilisation by HI with the cosolute was the dominating factor that determined the decrease in rate. ${ }^{12}$

Based on these observations, the groups of Professor M. J. Blandamer at Leicester University and our group developed a theory for a quantitative interpretation of the cosolute-induced rate effects. ${ }^{13}$ By combining thermodynamics and transitionstate theory we have shown that:

$$
\begin{aligned}
\ln \left(k_{\left(m_{c}\right)} / k_{\left(m_{c}=0\right)}\right) & = \\
& \frac{2}{R \cdot T \cdot m_{0}^{2}}\left(g_{(c-I S)}-g_{(c-T S)}\right) m_{c}-N \cdot \phi \cdot M_{l} \cdot m_{c}
\end{aligned}
$$

In this equation, $k_{\left(m_{c}\right)}$ is the (pseudo)-first-order rate constant for hydrolysis in an $m_{\mathrm{c}}$ molal aqueous solution of cosolute $\mathrm{c}$, $k_{\left(m_{\mathrm{c}}=0\right)}$ is the rate constant for hydrolysis in water, $m_{\mathrm{o}}$ is the hypothetical, ideal reference state (i.e. $\left.1 \mathrm{~mol} \mathrm{~kg}^{-1}\right), R$ is the gas constant, $T$ the absolute temperature (in K), $\left(g_{(\mathrm{c}-\mathrm{IS})}-g_{(\mathrm{c}-\mathrm{TS})}\right)$ is denoted as $G(\mathrm{c})$ and represents the difference in Gibbs energy of interaction between the cosolute and the reactants and the cosolute and the AC, respectively. Furthermore, $N$ is the number of water molecules involved in the r.d.s. $(N=2$ in the present case), $\phi$ is the practical osmotic coefficient for the cosolute solution of molality $m_{\mathrm{c}}$, and $M_{1}$ is the molal mass of water. In the case of highly dilute cosolute solutions, $\phi$ can be taken as unity. For a hydrophobic cosolute $g_{(\mathrm{c}-\text { Is) }}$ will be more favourable (and more negative) than $g_{(\mathrm{c}-\mathrm{TS})}$, leading to a negative $G_{(\mathrm{c})}$. The $G_{(\mathrm{c})}$ can be easily obtained from the slope of a plot of $\ln \left(k_{\left(m_{c}\right)}\right)$ $\left.k_{\left(m_{\mathrm{c}}=0\right)}\right) v s . m_{\mathrm{c}}$. At higher cosolute concentrations (and depending on the cosolute hydrophobicity) the plot starts to deviate from linearity indicating the onset of higher-order (i.e. larger than pairwise) interactions between reactants and the cosolute. The second term in eqn. (1) is a correction for the effect of the cosolute on the reactivity of water and can often be neglected for low cosolute concentrations.

$G_{(\mathrm{c})}$ values have been determined for many cosolutes ${ }^{8}$ and an attempt is being made to analyse these parameters in terms of additivity of functional group interactions (vide infra) ${ }^{14}$ Such
Table $1 G_{(\mathrm{c})}$ values for the water-catalysed hydrolysis of $\mathbf{1 a - d}$ in aqueous solution in the presence of three short-chain alcohols $\left(25^{\circ} \mathrm{C}\right)$

\begin{tabular}{cllr}
\hline & \multicolumn{3}{l}{$G_{\text {(c) }} / \mathrm{J} \mathrm{kg} \mathrm{mol}^{-2}$} \\
\cline { 2 - 4 } Ester & EtOH & $n$-PrOH & $n$-BuOH \\
\hline 1a & $-304 \pm 5$ & $-474 \pm 8$ & $-709 \pm 10$ \\
$\mathbf{1 b}$ & $-338 \pm 9$ & $-555 \pm 22$ & $-833 \pm 29$ \\
$\mathbf{1 c}$ & $-400 \pm 4$ & $-592 \pm 22$ & $-1044 \pm 54$ \\
$\mathbf{1 d}$ & $-466 \pm 22$ & $-634 \pm 52$ & $-1213 \pm 70$ \\
\hline
\end{tabular}

an additivity scheme represents a difficult and delicate issue because the hydration shells of functional groups in a single molecule tend to influence each other.

\subsection{Hydrophobic interactions between alcohols and esters - a case study}

In order to illustrate the information that can be obtained from our kinetic approach we now focus on a recent detailed and systematic study of the $G_{(c)}$ parameters for a few structurally closely related activated esters of varying hydrophobicity in the presence of three monohydric alcohols of gradually increasing hydrophobicity $(\mathrm{EtOH}, \mathrm{n}-\mathrm{PrOH}, \mathrm{n}-\mathrm{BuOH})$. The esters are 1a, $\left(\mathrm{R}=\mathrm{H}, \mathrm{k}_{\left(m_{c}=0\right)}=30.9 \times 10^{-4} \mathrm{~s}^{-1}\right), \mathbf{1 b}\left(\mathrm{R}=\mathrm{Me}, \mathrm{k}_{\left(m_{c}=0\right)}=11.7 \times\right.$ $\left.10^{-4} \mathrm{~s}^{-1}\right), \mathbf{1 c}\left(\mathrm{R}=\mathrm{Et}, \mathrm{k}_{\left(m_{c}=0\right)}=3.06 \times 10^{-4} \mathrm{~s}^{-1}\right)$ and $\mathbf{1 d}(\mathrm{R}=$ $\left.\mathrm{n}-\mathrm{Pr}, \mathrm{k}_{\left(m_{c}=0\right)}=2.73 \times 10^{-4} \mathrm{~s}^{-1}\right) .{ }^{15}$ Plots of $\ln \left(\mathrm{k}_{\left(m_{c}\right.} / \mathrm{k}_{\left(m_{c}=0\right)}\right)$ vs. $\mathrm{m}_{\mathrm{c}}$ are linear over the concentration range $0-0.9 \mathrm{~mol} \mathrm{~kg}^{-1}$. The $\mathrm{G}_{(\mathrm{c})}$ values, obtained from the slopes of these plots are given in Table 1 and are shown for the different ester/alcohol combinations in Fig. 2. The data show that $\mathrm{G}_{(\mathrm{c})}$ consistently becomes more negative with increasing hydrophobicity (i.e. increasing water-accessible surface area of the alkyl groups) of both the ester and the alcohol. ${ }^{16}$ On the basis of previous evidence we assume that it is the (standard) chemical potential of the reactant(s) that is determining $G_{(c)}$. The results are therefore fully reconcilable with the notion that the rate-retarding effects exercised by the alcohols find their origin in HI between the ester and the cosolute. The pairwise interaction indicates the formation of an encounter complex with a stability increasing with the hydrophobicity of both components. Recent MD simu-

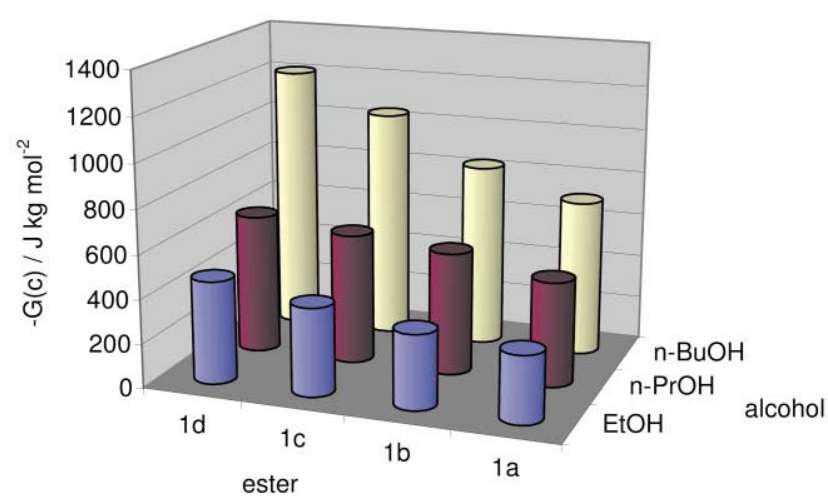

Fig. $2 G_{(\mathrm{c})}$ parameters for a set of structurally closely related activated esters of varying hydrophobicity in the presence of three monohydric alcohols of gradually increasing hydrophobicity. 
Table 2 Equilibrium constants ${ }^{a}$ and Gibbs energies ${ }^{b}$ for encounter complex formation of $\mathbf{1 b}-\mathbf{d}$ with three short-chain alcohols $\left(25^{\circ} \mathrm{C}\right)$

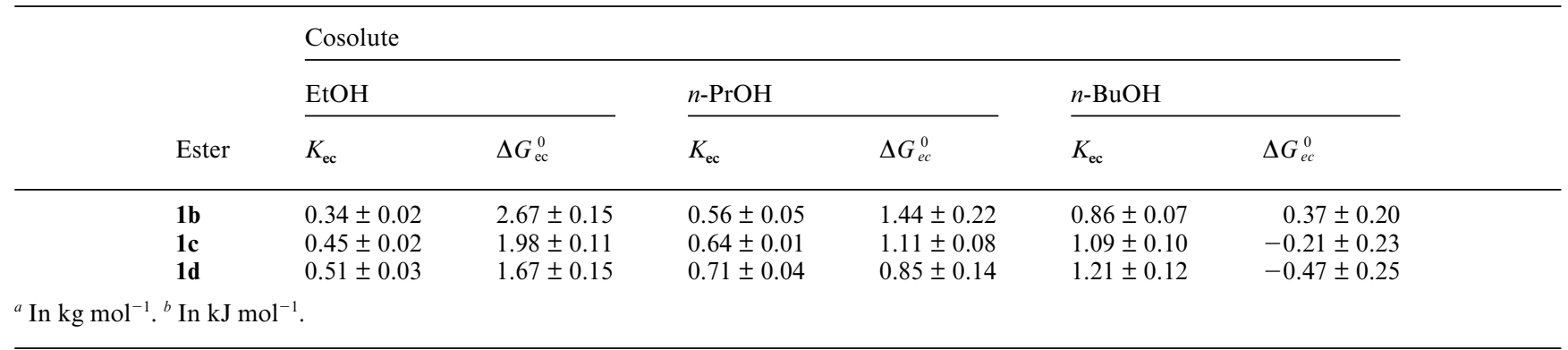

lations ${ }^{11}$ (vide supra) showed that formation of the AC needs a critical orientation of both water molecules attacking the ester carbonyl group. In the ester-alcohol encounter complex this water positioning is frustrated and it has been suggested that the encounter complex is not prone to hydrolysis or at leas reacts only slowly. ${ }^{14}$ Under these conditions one can show that:

$$
k_{\left(m_{c}\right)}=\frac{k_{\left(m_{c}=0\right)}}{1+K_{e c} \cdot m_{c}}
$$

in which $K_{\mathrm{ec}}$ is the equilibrium constant for formation of the encounter complex. Non-linear least-squares fitting of the rate data to eqn. (2) gave the $K_{\mathrm{ec}}$ values and the standard Gibbs energies for encounter complex formation, $\Delta G_{\mathrm{ec}}^{0}$ (Table 2). The $K_{\text {ec }}$ values increase with increasing hydrophobicity of the ester and alcohol. Solely for $n$-BuOH in combination with $\mathbf{1 c}$ and 1d are the $K_{\mathrm{ec}}$ values larger than unity. Enthalpies and entropies for encounter complex formation have been obtained for 1c and show the expected compensatory behaviour (Table 3 ). The positive values for $\Delta S_{\mathrm{ec}}^{0}$ are anticipated for HI of small molecules at room temperature (vide supra) and increase with increasing hydrophobicity of the alcohol. We also note that for these relatively weak $\mathrm{HI}$ the entropic term only dominates the enthalpic contribution for $n-\mathrm{BuOH}$. The enthalpy data suggests that the interaction between water and the hydrophobic reactants is enthalpically more favourable than that between the nonpolar solutes themselves.

Information about the structure of the encounter complex is difficult to obtain. In fact one can argue that the stability of the complexes is sufficiently close to the thermal energy that it is perhaps not reasonable to expect a well-defined structure, but that a variety of different arrangements is possible. Recent MD simulations $^{11 b}$ of the effect of $t-\mathrm{BuOH}$ and $\mathrm{EtOH}$ on the neutral hydrolysis of 4-methoxyphenyl dichloroacetate gave a quantitative measure for the effect of encounter complex formation on the reactive conformations from which the hydrolytic process can take place. However, no specific preferred binding region for the cosolute was found. These data were in satisfactory accord with the experimentally found rate retardations. The MD simulations also reproduced the linear correlation between $\ln \mathrm{k}_{\left(m_{\mathrm{c}}\right)}$ and the cosolute concentration.

Isobaric activation parameters for the hydrolysis of $\mathbf{1 c}$ as a function of the alcohol concentration in the highly aqueous region (up to $0.8 \mathrm{~mol} \mathrm{~kg}^{-1}$ ) are graphically given in Fig. 3. The dominating effect of $\Delta^{\neq} S^{\theta}$ in determining the rate points towards an entropy-driven hydrophobic stabilisation of the encounter complex.

Previously $\Delta^{\ddagger} H^{\theta} / \Delta^{\neq} S^{\theta}$ compensation behaviour has been found for a variety of organic reactions in the water-rich region and the changes in $\Delta^{\neq} H^{\theta}$ and $\Delta^{\neq} S^{\theta}$ have been described as capricious. ${ }^{15}$ Often ill-defined "water-structuring" effects have been proposed as an explanation. However, the advent of deeper insights into the origin of $\mathrm{HI}$ opened new avenues for the interpretation of the compensating effects of $\Delta^{\neq} H^{\theta}$ and $\Delta^{\neq} S^{\theta}$. Strong enthalpy-entropy compensation originates from the labile nature (in terms of $\Delta G$ ) of the hydrogen bonds in the hydrophobic hydration shell. The balance between a fully hydrogen-
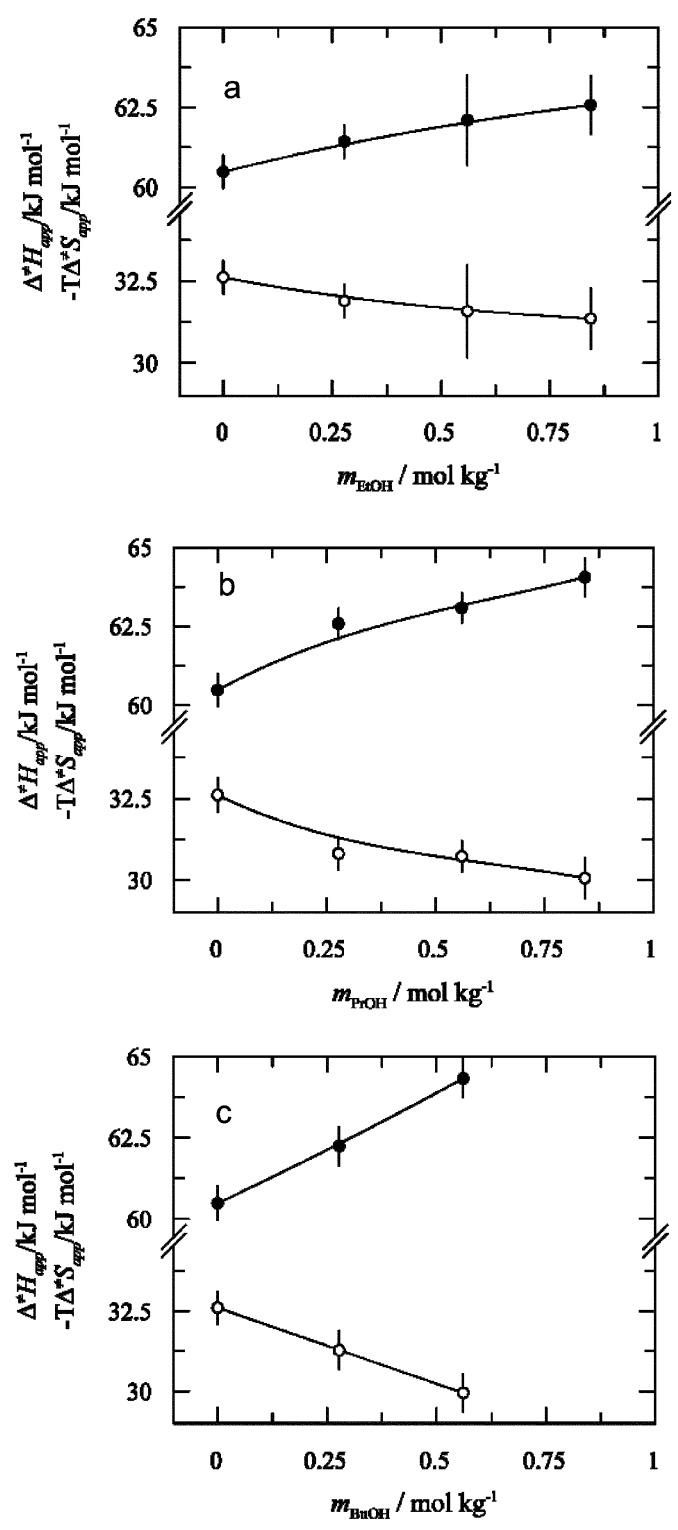

Fig. 3 Isobaric activation parameters for the hydrolysis of $\mathbf{1 c}$ in highly aqueous solvent mixtures as a function of the concentration of ethanol (a); 1-propanol (b); and 1-butanol (c).

bonded hydrophobic hydration shell and one, which features broken hydrogen bonds is delicate and easily swung in either direction. Breaking a hydrogen bond is costly in terms of enthalpy but results in a nearly compensating gain in entropy. It is likely that this effect is the main contributor to enthalpyentropy compensation. It also explains the large heat capacity change $(\Delta C \mathrm{p}$, the isobaric temperature dependence of $\Delta H)$ that is characteristic for hydrophobic hydration and interactions: it only takes a comparatively small increase in temperature to break hydrogen bonds in the hydrophobic hydration shell, which is accompanied by an increase in enthalpy. 
Table 3 Thermodynamics ${ }^{a}$ of encounter complex formation for $\mathbf{1 c}$ $\left(25^{\circ} \mathrm{C}\right)$

\begin{tabular}{lrll}
\hline & $\Delta G_{\mathrm{ec}}^{0}$ & $\Delta H_{\mathrm{ec}}^{0}$ & $T \Delta S_{\mathrm{ec}}^{0}$ \\
\hline EtOH & $1.98 \pm 0.11$ & $4.95 \pm 0.50$ & $2.97 \pm 0.52$ \\
$n$-PrOH & $1.11 \pm 0.08$ & $7.71 \pm 0.92$ & $6.60 \pm 0.93$ \\
$n$-BuOH & $-0.21 \pm 0.23$ & $6.68 \pm 0.82$ & $6.89 \pm 0.85$ \\
${ }^{a}$ All data in $\mathrm{kJ} \mathrm{mol}^{-1} \cdot$ & & \\
\hline
\end{tabular}

\subsection{Higher-order interactions}

Apart from structural information regarding the (highly dynamic) encounter complexes, another major issue that awaits further study is the precise composition of the encounter complex with an inert cosolute. Although it seems clear that the stability (expressed in $K_{\text {ec }}$ ) is increasing with the hydrophobicity of reactant and the cosolute, the question remains at which cosolute concentration higher-order interactions start to contribute significantly. This problem has been addressed recent$1 y,{ }^{14 b}$ assuming that higher-order interactions mainly originate from $1: 1$ interactions between the substrate (concentration $c a$. $10^{-4} \mathrm{~mol} \mathrm{~kg}^{-1}$ ) and a cluster formed from cosolute molecules. If $K_{\text {ecc }}$ is the equilibrium constant for encounter complex formation between the substrate and clusters, it was estimated that $K_{\text {ecc }}$ was $c a$. 2-4 times smaller than $K_{\text {ec }}$ for hydrolysis of 1a-d in the presence of the three alcohols. Apparently, clustering of the cosolutes reduces their propensity to interact with the substrate as some of the hydrophobic surface of the cosolvent is buried inside the cluster.

\subsection{Additivity of functional group interactions}

Using a reductionist approach we have asked the question how far HI in encounter complexes can be dissected into contributions of the individual functional groups that are contained within the substrate and cosolvent molecules. This approach provides insight into the aqueous solvation of various functional groups. Where additivity holds the functional groups are solvated independently of one another; i.e. the influence of the solvation sphere of a particular functional group on those of neighbouring functional groups is minimal. Hence, the influence of the functional group on its solvation must be of short range. However, when additivity breaks down, the solvation sphere of neighbouring functional groups influence each other ${ }^{17}$ and the influence of the functional group on the arrangement of the surrounding water molecules must be longer-ranged.

We have re-expressed eqn. (1) using a quasi-group additivity approach: ${ }^{13,18}$

$$
\begin{aligned}
& \ln \left(\left(k_{\left(m_{c}\right)}\right) /\left(k_{\left(m_{c}=0\right)}\right)\right)= \\
& \frac{2}{R T m_{0}^{2}}\left[\sum_{i} n_{i}^{c} g_{(I S-i)}-\sum_{i} n_{i}^{c} g_{(T S-i)}\right] m_{c}-N \phi M_{l} m_{c}
\end{aligned}
$$

in which $g_{(\mathrm{IS}-i)}$ and $g_{(\mathrm{TS}-i)}$ are the pairwise Gibbs energies of interaction of, respectively, reactants and $\mathrm{AC}$ with groups $i$ in the cosolvent. The term $G_{\mathbf{c}}\left(g_{(\mathrm{c}-\mathrm{IS})}-g_{(\mathrm{c}-\mathrm{TS})}\right)$ in eqn. (1) is now replaced by the term between brackets in eqn. (3). In terms of the Savage-Wood additivity of group interactions approach, one can use

$$
g\left(\mathrm{CH}_{3}\right)=1.5 g\left(\mathrm{CH}_{2}\right)=3 g(\mathrm{CH})
$$

For the cosolute effect of $\mathrm{CH}_{3} \mathrm{OH}$ one can use:

$$
g\left(\mathrm{CH}_{3} \mathrm{OH}\right)=3 g(\mathrm{CH})+g(\mathrm{OH})
$$

whereas:

$$
g\left(\mathrm{CH}_{3} \mathrm{CH}_{2} \mathrm{OH}\right)-g\left(\mathrm{CH}_{3} \mathrm{OH}\right)=g\left(\mathrm{CH}_{2}\right)=2 g(\mathrm{CH})
$$

Additivity holds reasonably well for monohydric alcohols ${ }^{12 a}$ but breaks down for most other polar groups, ${ }^{17}$ suggesting that hydrocarbon and isolated $\mathrm{OH}$-groups have only a short-range influence on the arrangement of water molecules.

Interestingly, dissolution of apolar organic molecules in water is characterised by large and positive heat capacity changes as anticipated on the basis of the strong temperature dependence of the highly dynamic 3-D hydrogen-bond network of water. Group additivity is also found for these heat capacities: nonpolar $\mathrm{CH}$ groups contribute an approximately constant value for a large group of solutes. ${ }^{19}$

\subsection{Hydrophobic sugars?}

Measurements of $G_{(\mathfrak{c})}$ values have allowed kinetic studies of medium effects to serve as useful tools for the study of $1: 1$ interactions governed by HI. So far, the results have been satisfying and in some cases have led to rather surprising results. For example, when using a series of hexoses as cosolutes we found that these molecules interacted with the probe molecules as if they were hydrophobic. This unexpected behaviour has been rationalised in terms of "camouflage effects". This refers to the comparability of the relative distances of the next-nearest neighbour oxygen atoms in the hexose with the oxygen-oxygen distances in water which describes the "fit" of the hexose into the 3-D hydrogen-bond structure of water. ${ }^{20}$ The better this fit, the more negative the $G_{(\mathrm{c})}$ values and the more the hexoses behave as hydrophobic cosolutes, almost as if their OH-groups were not there. Of course the $\mathrm{OH}$-groups are still there; they are covalently linked to the hydrocarbon backbone and therefore no direct hydrophobic contact between this backbone and the probe can take place. This behaviour almost hints at the existence of a solvent-separated mode of HI. Such HI have been observed in computer simulations but are controversial, particularly in view of the fact that there is no solid experimental evidence.

\section{Influence of hydrophobic interactions on chemical reactivity}

Nature makes extensive use of HI for binding of substrates to enzymes. There are no fundamental reasons why HI could not be an equally useful tool for the organic chemist. However, HI in connection with organic chemistry are relatively unexplored and deliberate use of these interactions to drive chemical reactions or to tune the selectivity thereof is rare. To some extent this is a result of the fact that HI only exist in water, and that water has, for a long time, not been the most popular solvent amongst organic chemists. This 'hydrophobia' no doubt originates from the fact that water is often a poor solvent for nonpolar compounds and that it is a relatively reactive solvent. However, the last two decades have brought a reappraisal of water as a green solvent suitable for an unexpectedly wide range of organic reactions. ${ }^{21}$ For example, many Lewis-acid catalysed reactions and reactions involving organometallic reagents have been found to be compatible with aqueous solvents and frequently these reactions even benefit from the use of water. ${ }^{21}$ Although it is clear that water plays a unique role in many of these reactions, it is generally much less clear what exactly the interactions between water and the reacting molecules are that influence reactivity. We will now discuss a number of relatively simple organic reactions for which mechanistic understanding is sufficiently developed and from which we will extract some generalities and directions for promising further developments.

\subsection{Diels-Alder reactions ${ }^{22}$}

The observation by Rideout and Breslow in 1980 that Diels-Alder reactions are accelerated in water as compared to organic solvents marks a turning point in the organic chemist's conception of water as a solvent for organic reactions. ${ }^{23}$ The 


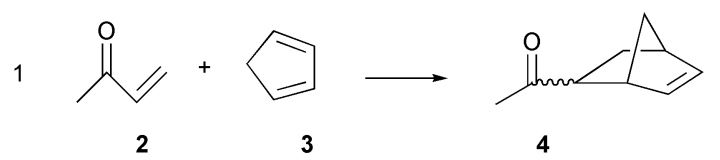

2

3

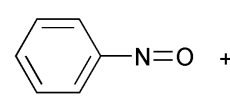<smiles>C1=CCCC=C1</smiles>

8<smiles>COc1cccc2c1C(=O)C1C3C=CC(C3)C1C2=O</smiles><smiles></smiles>

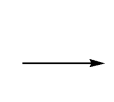<smiles>C1=CC2CCC1ON2c1ccccc1</smiles>

aprotic $\quad \mathrm{F}_{3} \mathrm{C} \stackrel{\mathrm{OH}}{=} \mathrm{CF}_{3} \quad \mathrm{H}_{2} \mathrm{O}$

100

290

$\left(\mathrm{CH}_{3} \mathrm{CN}\right)$

(2)

4320

12800

1
(n-hexane)

1
toluene)

5.49

44.3

Scheme 2 Effect of water on the rate constants of a number of Diels-Alder reactions. The rate constants are given relative to the least polar solvent. Data taken from ref $40 a$ (entry 1 and 2) and ref 26 (entry 3).

Diels-Alder reaction was the textbook example of an organic reaction that is insensitive to the nature of the solvent. For instance, the rate of dimerisation of cyclopentadiene only varies by a factor of maximally 4 in different organic solvents. ${ }^{24}$ However, Diels-Alder reactions in water turned out to be accelerated by factors up to $10^{4}$ when compared to organic solvents (Scheme 2). These remarkable accelerations were initially attributed exclusively to HI. However, careful investigation subsequently revealed that hydrogen bonding by water to the activating groups (usually carbonyl or nitrile moieties) in the ACs also plays an important role. The relative contributions of activation through hydrogen bonding and HI vary with the nature of the reactants. We will focus here on the hydrophobic part of the acceleration, the mechanism of which has been studied in considerable detail. It is easy to rationalise that Diels-Alder reactions benefit from HI: two relatively nonpolar molecules react to form a single product molecule, which implies that the nonpolar surface area that is exposed to water is reduced during the activation process. Some of the water molecules that formed part of the hydrophobic hydration shell surrounding the reactants are liberated during the reaction, and release of these molecules into bulk solvent provides an additional driving force for the reaction (Fig. 4). This is an example of an 'enforced' hydrophobic interaction in which an organic reaction forces nonpolar entities into close proximity. Entry 3 in Scheme 2 illustrates the extent of acceleration that can be achieved solely through HI. The dienophile in this Diels-Alder reaction is nitrosobenzene (7), the reactivity of which is not significantly influenced by hydrogen bonding, ${ }^{25}$ so that only the hydrophobic part of the effect of water remains. ${ }^{26}$
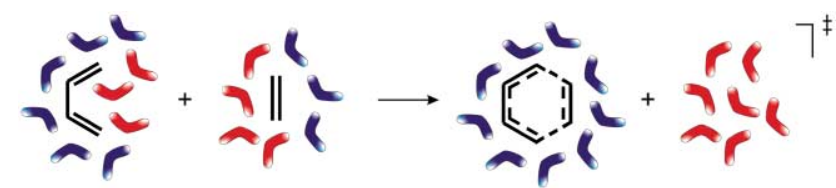

Fig. 4 Schematic representation of the hydrophobic hydration shells surrounding starting materials and activated complex of a Diels-Alder reaction. The regions marked in red indicate parts of the hydration shell that are released into bulk solution upon reaction.

The study of the effect of water on the relative stabilities of the reactants, ACs and products of the Diels-Alder reaction has led to some unexpected revelations. Using vapour pressure measurements it is possible to determine the Gibbs energy of transfer of a solute from one solvent to the other. These data have been obtained for the transfer of cyclopentadiene and methyl and ethyl vinyl ketone from 1-propanol to water and combined with the Gibbs energies of activation for the reactions of these molecules in these two solvents. ${ }^{27}$ As expected from the nonpolar nature of the reactants, the IS is destabilised in water as compared to 1-propanol. A surprisingly comparable destabilisation is observed for the products. Since the geometries of product and $\mathrm{AC}$ of the Diels-Alder reaction are very similar, one would expect to find a similar destabilisation upon transfer of the AC from 1-propanol to water. Surprisingly, this is not observed: the Gibbs energy of the transition state (TS) is almost the same in the two solvents. This suggests that, even though the geometry of AC and product are similar, the electronic nature of the two species is significantly different, in that the $\mathrm{AC}$ is able to interact much more efficiently with the surrounding water molecules than the reactants. The AC seems to have lost its hydrophobic character entirely. These findings were confirmed in a separate study in which hydrophobic substituents were introduced at various distances from the reacting $\pi$-systems of the Diels-Alder reactions between $N$-alkyl maleimides (10) and dienes 3 and 12 (Fig. 5). ${ }^{28}$ When compared to 1-propanol, the ISs in water were destabilised upon introduction of the hydrophobic substituents irrespective of the exact location of these substituents. Since the substituents do not actively participate in the reaction one would not expect their solvation to change much during the reaction and therefore their effect on the TSs should be similar to those on the IS; i.e. they cancel out in their effect on the rate of the reaction. However, only the substituents remote from the reacting $\pi$-systems behaved in this way, whereas substituents close to the reacting bonds turned out to completely loose their hydrophobic character in the AC (Fig. 5). Thus, Diels-Alder reactions seem to benefit from enforced $\mathrm{HI}$ much more than expected on the basis of a simple reduction of surface area in contact with water. It is at present unclear what exactly causes this behaviour but it seems likely that the highly polarisable electronic nature of the AC plays an important role and it seems that these electronic effects are not limited to the reacting atoms but are also felt by those nearby.

The isobaric thermodynamic activation parameters of the Diels-Alder reaction in various solvents have been studied. It is difficult to disentangle the thermodynamic contributions resulting from activation by hydrogen bonding from those due to enforced HI. However, it is probably not unreasonable to assume that the changes in enthalpy and entropy of activation upon going from aprotic 1,4-dioxane to methanol are due to 

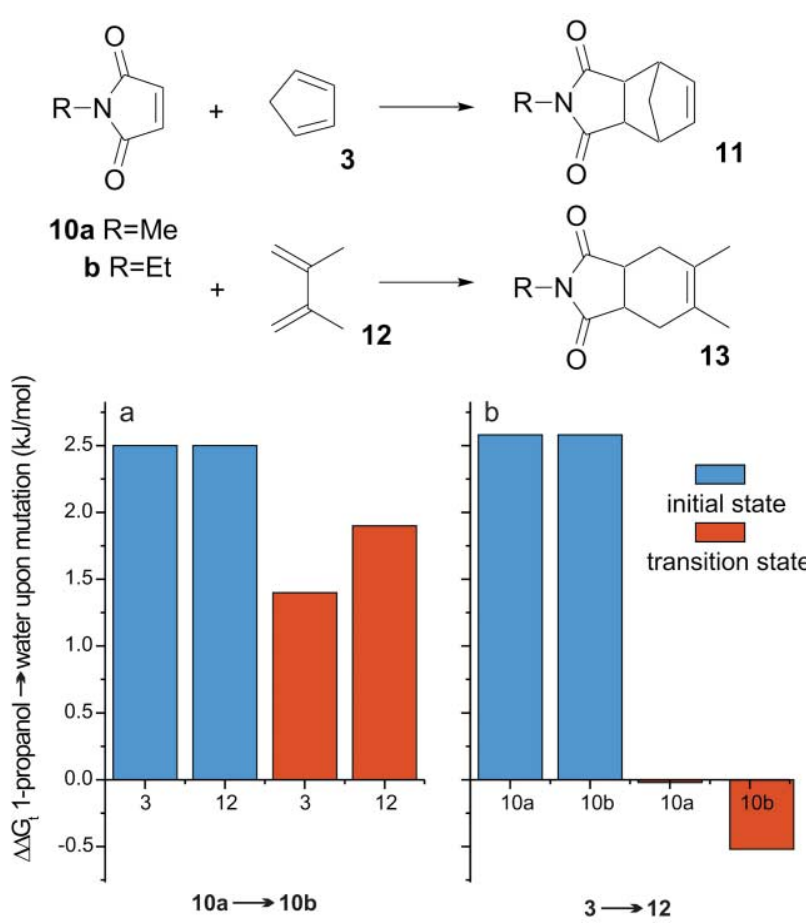

Fig. 5 Effect of increasing the hydrophobicity of the reactants on the Gibbs energy of transfer of reactants and activated complex from 1-propanol to water, showing (a) the effect of elongating the alkyl group in 10 by one methylene unit (10a to 10b) and (b) the effect of substituting 3 for the more hydrophobic 12. Data taken from ref. 28.

hydrogen-bond activation, whereas the changes from methanol to water will be dominated by enforced HI. It turns out that, for the Diels-Alder reaction of methyl vinyl ketone with cyclopentadiene, the acceleration upon going from 1,4-dioxane to methanol is mainly enthalpic in origin, ${ }^{29}$ whereas the additional rate enhancement upon going from methanol to water is dominated by entropy. ${ }^{30}$ Such an entropic driving force is expected for HI between small molecules in pure water at ambient temperatures (vide supra).

Further insight into the effect of enforced HI on Diels-Alder reactions has been obtained using computer simulations. ${ }^{31}$ These studies confirm the importance of enforced HI alongside activation by hydrogen bonding and allow the separation of the two effects. The most recent simulation of a set of typical Diels-Alder reactions suggests that the lowering of the activation barrier as a result of $\mathrm{HI}$ amounts to approximately $1 \mathrm{kca}$ $\mathrm{mol}^{-1}$, which corresponds to a rate enhancement by approximately a factor of 5 under ambient conditions. ${ }^{31 g}$ This appears to be a rather conservative estimate when compared to experimental data.

\subsection{1,3-Dipolar cycloadditions}

Like Diels-Alder reactions, 1,3-dipolar cycloadditions are concerted and nearly synchronous processes with little change in polarity during the reaction. In fact, many compounds that are reactive as dienophiles in Diels-Alder reactions can also be used as dipolarophiles. Solvent effects on 1,3-dipolar cycloadditions are generally even smaller than those on Diels-Alder reactions. Given these similarities one would expect that also 1,3-dipolar cycloadditions can benefit from HI, which they do. However, as with Diels-Alder reactions, acceleration due to hydrophobic effects are not easy to separate from effects due to activation by hydrogen bonding. Whereas for the Diels-Alder reaction these two effects usually work in the same direction, the presence of the 1,3-dipole offers additional hydrogenbonding possibilities. Depending on the nature of the 1,3-dipole, hydrogen bonding can in some cases result in stabilisation of the FMOs of this species, increasing the HOMO-LUMO
Table 4 Solvent effect on the rate of the Claisen rearrangement of a set of allyl vinyl ethers ${ }^{a}$

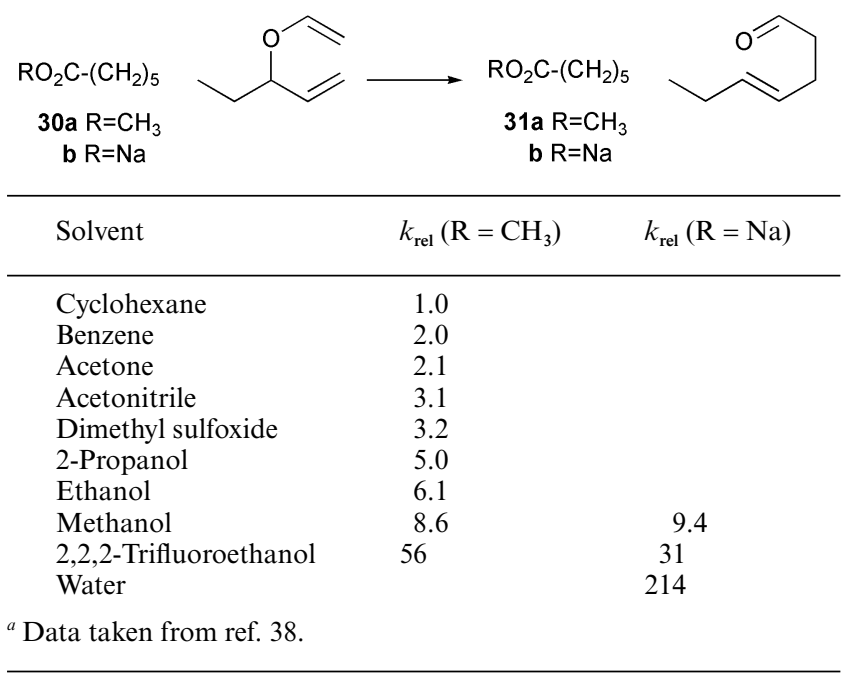

gap and thereby reducing the rate of the reaction. ${ }^{32}$ This effect counteracts the accelerating influence of enforced HI. As a result the overall effect of water on the rate of 1,3-dipolar cycloadditions can be accelerating or retarding, depending on the nature of the reactants (vide infra). Although the kinetics of 1,3-dipolar cycloadditions has already been studied in $1978,{ }^{33}$ it took until 1991 before the unusual influence of water on this reaction was first noticed. ${ }^{34}$ Scheme 3 provides an overview over the kinetic studies on the effect of water on 1,3-dipolar cycloadditions. Nitrile oxides are among the most extensively studied dipoles and the effect of water on the cycloadditions of these compounds is modest. Work by Gholami et al. ${ }^{35}$ suggests that hydrophobic effects can enhance the reaction rate even when the nonpolar groups are remote from the reaction centre. Whereas the rate for the reaction of dimethyl fumarate $\mathbf{2 3}$ is hardly affected by a change of solvent from $n$-hexane to water, the same change in solvent causes di- $n$-butyl fumarate $\mathbf{2 4}$ to react more than 10 times faster (Scheme 3, entry 3).

Computer simulations by Repasky and Jorgensen confirmed the beneficial influence of $\mathrm{HI}$ on the rate of 1,3-dipolar cycloadditions in water. ${ }^{36}$

\subsection{Claisen rearrangements ${ }^{37}$}

In addition to the Diels-Alder reaction and the 1,3-dipolar cycloaddition, the Claisen rearrangement is another member of the family of pericyclic reactions and is characterised by a concerted mechanism and the absence of significant changes in charge separation in the course of the reaction. Even though the Claisen rearrangement is a unimolecular process, it has a negative volume of activation, indicating a reduction of the surface area of the reactant during the reaction. Hence, also Claisen rearrangements should be accelerated through HI.

Table 4 shows the solvent effect on the Claisen rearrangement of an allyl vinyl ether carrying a solubilising side group. ${ }^{38}$ The nature of the solubilising group had to be varied to allow for kinetic measurements in a wide range of solvents. The rate constants for the rearrangements of the two allyl vinyl ethers (30a and 30b) in solvents of intermediate polarity (in which both substrates were soluble) were similar, indicating that direct comparison of the rate constants across the two substrates is legitimate. The data shows that the rearrangement is accelerated by a factor of 214 in going from cyclohexane to water. Gajewski performed a multiparameter analysis on the solvent effect, demonstrating the importance of two solvent parameters: the hydrogen-bond donating capability and the cohesive energy density (a measure of the interaction energy between the solvent molecules). ${ }^{39}$ In the case of water, both effects were found to contribute to nearly equal extents. Similar to the 
<smiles>[O-][N+]#Cc1c(Cl)cccc1Cl</smiles>

14<smiles>CC1=CC(=O)C(C)=CC1=O</smiles><smiles>CC1=CC(=O)C2(C)ON=C(c3c(Cl)cccc3Cl)C2C1=O</smiles>

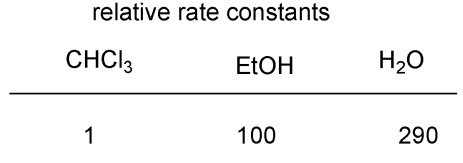

\begin{tabular}{ccc} 
n-hexane & $\mathrm{CF}_{3} \mathrm{CH}_{2} \mathrm{OH}$ & $\mathrm{H}_{2} \mathrm{O}$ \\
\hline 1 & 1.3 & 3.3
\end{tabular}

2<smiles>[O-][N+]#Cc1ccccc1</smiles>

17<smiles>C[C@H]1C=COC1</smiles><smiles>[12FH]</smiles><smiles>C=CC(C)=O</smiles><smiles>C=CC=N</smiles>

20<smiles>CN1C(=O)C=CC1=O</smiles>

$10 a$<smiles>C1=CCCC1</smiles><smiles>CCCC</smiles><smiles>[R]C1ON=C(c2ccccc2)C1[R]</smiles>

1<smiles>[O-][N+]([O-])=C(c1ccccc1)c1ccccc1</smiles><smiles>COC(=O)/C=C/C(=O)OC</smiles><smiles>[R]OC(=O)C1ON(c2ccccc2)C(c2ccccc2)C1C(=O)O[R]</smiles>

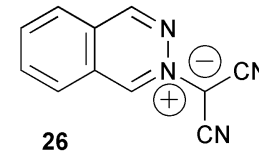<smiles>C=CC(C)=O</smiles><smiles>CCCC1(C#N)CC(C#N)(C#N)N2N=Cc3ccccc3C21</smiles><smiles>CC(C)C(C)O</smiles><smiles>CC(C#N)[n+]1ccccn1</smiles><smiles>C=CC(C)=O</smiles><smiles>CCCCCCC</smiles><smiles>CC(=O)[C@@H]1CC(C#N)(C#N)N2N=CC=CC12</smiles>

29

Scheme 3 Effect of water on the rate constants of a number of 1,3-dipolar cycloaddition reactions. The rate constants are given relative to the least polar solvent. Data taken from ref 34 (entry 1); ref 32 (entry 2); ref 35 (entry 3) and ref 58 (entry 4).

Diels-Alder reaction, ${ }^{40}$ the hydrophobic part is mainly a result of destabilisation of the IS of the reaction, whereas hydrogen bonding predominantly affects the TS. ${ }^{37 b}$

Studies of the effect of water on the Claisen rearrangement using computer simulations mainly emphasised the importance of hydrogen bonding. ${ }^{41}$

\subsection{Other reactions that benefit from hydrophobic interactions}

The best-documented examples of organic reactions that benefit from HI have been summed up above and all happen to fall into the same class of pericyclic reactions. However, there are a number of examples that prove that hydrophobically accelerated reactions are by no means restricted to these types of reactions. A good example is the solvolysis of tert-butyl chloride. This textbook example of an $\mathrm{S}_{\mathrm{N}} 1$ reaction is accelerated in polar and protic solvents as these stabilise the dipolar $\mathrm{AC}$ and the developing negative charge on the chloride leaving group. However, as reiterated by Gajewski, ${ }^{37 b}$ the solvolysis of tert-butyl chloride in water is much faster than would be expected solely on the basis of the polarity and hydrogen-bonding characteristics of water. Work by Abraham et al. ${ }^{42}$ have demonstrated that the hydrophobic character of the reactant causes the IS to be destabilised in water when compared to organic solvents. No such destabilisation occurs for the TS, featuring a polar AC (Fig. 6). 


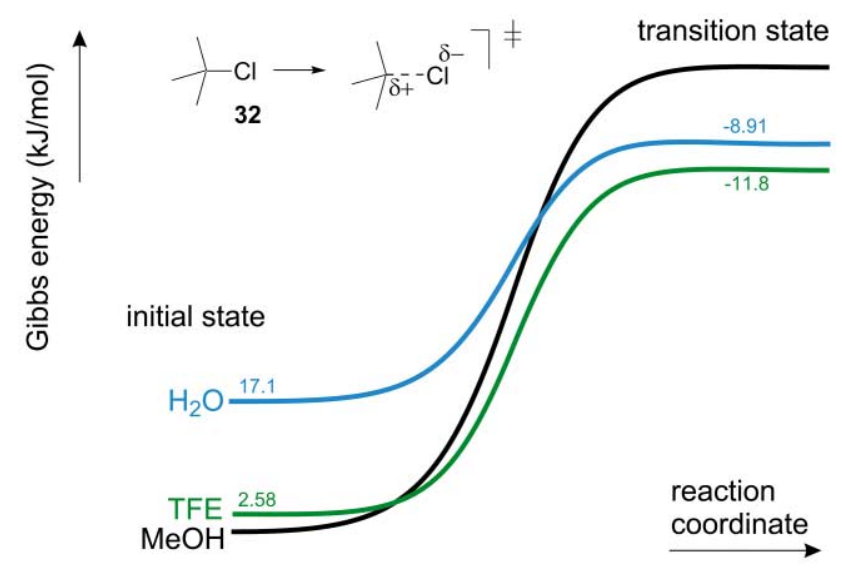

Fig. 6 Hydrophobic destabilisation of the initial state of the solvolysis of tert-butyl chloride results in an increase in the rate of this reaction in water compared to other polar protic solvents. Data taken from ref 42 and corrected ${ }^{1 d}$ to a mol L ${ }^{-1}$ standard state.

Lubineau ${ }^{43 a, b}$ and Meyer ${ }^{43 b}$ have investigated the effect of water on the Mukaiyama aldol reaction (Scheme 4). This reaction features nonpolar molecules and is characterised by a negative volume of activation, two ingredients that make it a promising candidate for rate enhancements through HI. Comparison of the yields after various reaction times and at various temperatures indicated that the reaction did indeed benefit dramatically from the use of water as the solvent. Water also altered the selectivity in favour of the syn product. Unfortunately, the low solubility of the reactants necessitated that the reactions were performed under heterogeneous conditions, which makes it difficult to draw any mechanistic conclusions. More recently, Loh and coworkers reported a similar acceleration of a series of aldol reactions in water. ${ }^{44}$ Although HI might well play a role in accelerating aldo reactions, more detailed mechanistic studies are required before definite conclusions can be drawn about the exact influence of water on this important organic reaction.

Recently radical cyclisations were found to benefit significantly from the use of water as compared to a wide range of organic solvents. ${ }^{45}$ This is a surprising result since solvent effects on radical reactions are usually believed to be small. The authors attributed the beneficial effect of water to a combination of the exceptionally high dielectric constant of water and hydrophobic effects.

\subsection{Effect of self-coiling on reactivity}

Jiang and coworkers have published a series of interesting papers describing the effects of self-coiling of elongated nonpolar molecules on their reactivity. The authors have studied the rates of hydrolysis of 4-nitrophenol esters containing long alkyl chains in mixed aqueous solvents (Scheme 5, entry 1). ${ }^{46}$<smiles>C[Si](C)(C)OC1=CCCCC1</smiles>

33<smiles>O=C1CCCCC1[C@H](O)c1ccccc1</smiles>

35 (syn)<smiles>O=Cc1ccccc1</smiles>

34<smiles>O=C1CCCC[C@]1(O)C(O)c1ccccc1</smiles>

36 (anti)
Scheme 4 Example of a Mukaiyama aldol reaction that benefits from the use of water as a solvent. ${ }^{43}$

Introduction of a thiol group at the end of the alkyl chain of 37b induced a large enhancement of the rate of the hydrolysis reaction in the more aqueous solvent mixtures as compared to the parent compound 37a. This effect increased with increasing amount of water in the solvent, but was completely absent in relatively nonpolar media. The effect was ascribed to neighbouring-group participation by the nucleophilic sulfur terminus. Extensive self-coiling is required for the two ends of the molecule to meet, which only appears to occur in more waterrich media through stabilisation of the coiled conformations by HI. Possible effects due to intermolecular aggregation were excluded as the rate of hydrolysis of $\mathbf{3 7} \mathbf{b}$ was found to be concentration independent.

Whereas hydrophobically-induced neighbouring-group participation by a sulfur atom sixteen carbon atoms away from the reacting centre may seem an oddity and only of academic interest, the underlying principle can be very useful in the synthesis of large-ring compounds. Jiang et al. ${ }^{47}$ have elegantly demonstrated this using a $[2+2]$ cycloaddition between two alkene groups separated by a 16-atom spacer (Scheme 5, entry 2). The rate of cyclisation of $\mathbf{4 0 b}$ was found to increase 20-fold upon increasing the volume fraction of water in DMSO from 40 to 70. No such solvent effect was found for $\mathbf{4 0 a}$, which has only a 6-atom spacer. Thermodynamic analysis revealed a dominant entropic contribution to the acceleration, whereas the enthalpy of activation was almost solvent-independent.

In another interesting study Fan and Jiang demonstrate how the effect of substituents on the rate of hydrolysis of long-chain esters can change upon changing the solvent composition. ${ }^{48} \mathrm{At}$ $30 \%(\mathrm{v} / \mathrm{v})$ water in DMSO the rate constants were found to correlate with Hammett's $\sigma$ constants, whereas at $45 \%$ water good correlations were obtained with Rekker's hydrophobic $f$ constants. This changeover was explained in terms of selfcoiling and aggregation of the substrates.
1

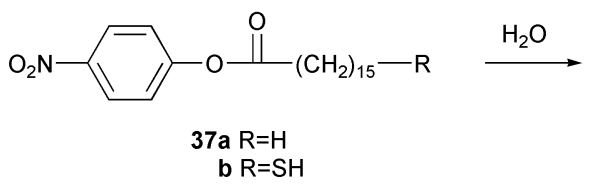<smiles>O=[N+]([O-])c1ccc(O)cc1</smiles>

38<smiles>[2H][13CH2]CC(=O)O</smiles>

39

2

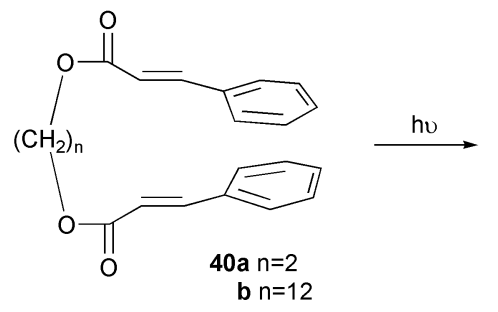<smiles>[Z14]OC(=O)[C@@H]1[C@@H](c2ccccc2)[C@H](c2ccccc2)[C@H]1C(=O)OC</smiles><smiles>CCOC(=O)[C@H]1[C@@H](c2ccccc2)[C@H](c2ccccc2)[C@H]1C(=O)OCC</smiles>

Scheme 5 Examples of how self-coiling induced by hydrophobic interactions can affect reactivity. Data taken from ref 46 (entry 1) and 47 (entry 2). 


\subsection{Hydrophobic effects as a mechanistic tool}

It is well established that certain salts decrease the solubility of nonpolar compounds in water, whereas other salts and cosolvents increase the solubility. Breslow and coworkers have used these effects as indicators for the involvement of $\mathrm{HI}$ in organic reactions in water. The authors reason that when a reaction in water is retarded by the addition of an 'antihydrophobic' salt or cosolvent, this indicates that the reaction is accompanied by a reduction in hydrophobicity in going from reactants to the $\mathrm{AC}$, which suggests close contact of nonpolar regions of the reacting molecules in the AC. ${ }^{49}$ This approach should be used carefully, as it is only valid when the cosolvent or salt do not have any direct effect on the rate of the reaction. There are a number of examples where it is reasonable to assume this is the case. The benzoin condensation is one such example (Scheme 6). Even though this reaction is faster in formamide and DMSO than it is in water, the rate in water seems to benefit from HI, resulting from close contact between the aromatic rings in the AC. ${ }^{50}$
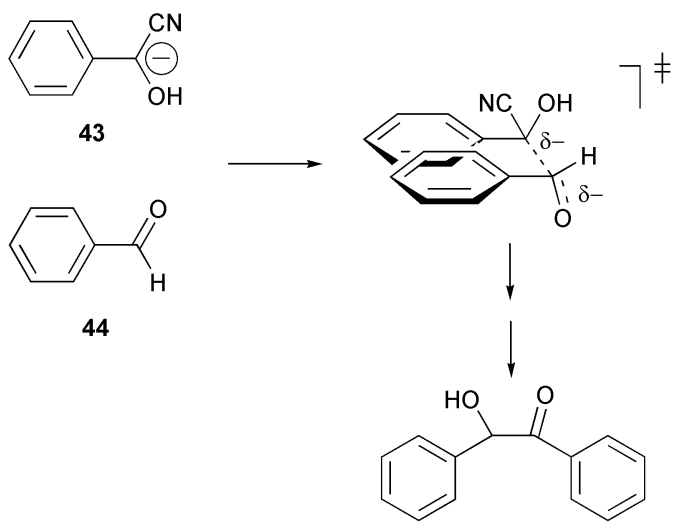

45

Scheme 6 The benzoin condensation in water benefits from hydrophobic interactions between the aromatic rings in the activated complex..$^{50}$

Breslow and coworkers have extended their approach of using salt and cosolvent effects to assess the change in solvent accessible surface area during the reaction from which conclusions can be drawn about the geometry of the AC. ${ }^{50 b, 51}$ Their studies led to some interesting suggestions concerning the geometries of the ACs of a series of $\mathrm{S}_{\mathrm{N}} 2$ substitution reactions (Scheme 7). ${ }^{51 a, 52}$ The rate constant for substitution at the benzylic position of $\mathbf{4 6}$ by phenolate nucleophile $\mathbf{4 7}$ is unaffected by addition of $20 \%(\mathrm{v} / \mathrm{v})$ ethanol cosolvent whereas the rate constant for the corresponding reaction with amine nucleophile 49 is almost halved by the addition of the cosolvent. This suggests that the reaction between $\mathbf{4 6}$ and $\mathbf{4 9}$ is accompanied by a reduction in solvent-accessible surface area whereas during the reaction between $\mathbf{4 6}$ and $\mathbf{4 7}$ the solvent-exposed surface area does not change. This can be rationalised by assuming AC geometries shown in Scheme 7 in which the amine nucleophile reacts through a stacked arrangement, whereas the phenolate ion attacks using its oxygen's sigma electrons, rather than one of its $\pi$ lone pairs. However, this interpretation is speculative. The reaction with the phenolate anion involves charge dispersal, whereas reaction with the neutral aniline nucleophile is accompanied by charge separation. Even without the involvement of HI this could lead to different cosolvent effects for the two reactions. ${ }^{52 c}$

\subsection{Influence of hydrophobic interactions on selectivity}

HI can result in accelerations of a variety of organic reactions in water by one to two orders of magnitude, when compared to organic solvents. One could argue that on the grand scale of solvent effects, these numbers are relatively small. However, when the selectivity of organic reactions is concerned, an order of magnitude is indeed significant. Hence, when an organic reaction has competing pathways that produce different products and these pathways are accompanied by different changes in the solvent-accessible nonpolar surface areas, then hydrophobic effects can be a powerful tool to influence product selectivity.

One of the earliest examples of the beneficial influence of HI on selectivity features once again the Diels-Alder reaction. Most Diels-Alder reactions give a mixture of endo and exo products. The AC leading to the endo product is more compact than that leading to the exo product, as evident from the smaller volume of activation for the endo pathway. ${ }^{53}$ Hence, the reaction leading to endo product will be accompanied by a greater reduction in solvent-exposed hydrophobic surface area than the process leading to exo product. Endo-exo selectivities therefore benefit from the use of water as HI selectively speed up the endo pathway. ${ }^{54}$ In addition, water further enhances the endo-exo ratio by a combination of its high polarity and good hydrogen-bond donating capacity. ${ }^{22}$

Also the selectivity of the 1,3-dipolar cycloaddition can be influenced by HI. ${ }^{55}$ Recent work by Breslow and coworkers suggests a role of $\mathrm{HI}$ in the competition between $C$-alkylation and $O$-alkylation of substituted phenolate ions. ${ }^{52}$

HI can also be used to improve the enantioselectivity of organic reactions in water. We have used $\alpha$-amino acids as ligands for $\mathrm{Cu}$ (II) ions in a Lewis-acid catalysed Diels-Alder reaction in water. ${ }^{56}$ When using the commercially available $N^{\alpha}$ methyltryptophan as ligand the Diels-Alder product was obtained in 74\% enantiomeric excess (Scheme 8). The enantioselectivity presumably results from an interaction between the indole ring of the $\alpha$-amino acid and the pyridine ring of the dienophile 51, shielding one face of the dienophile from
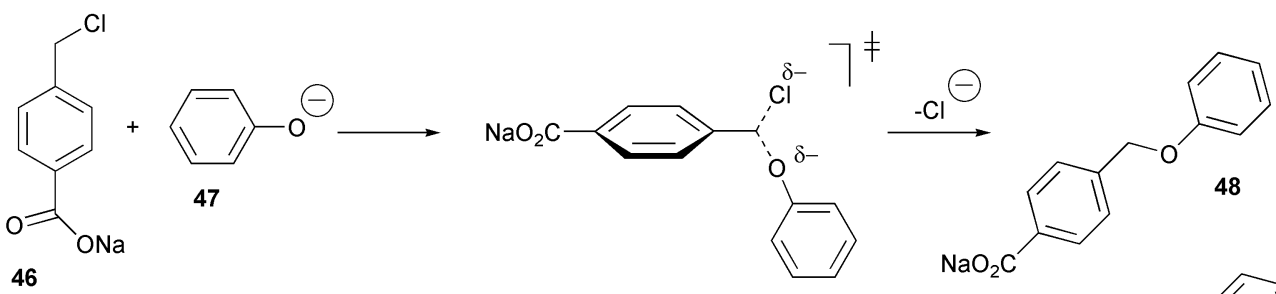

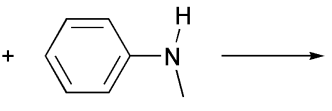

49

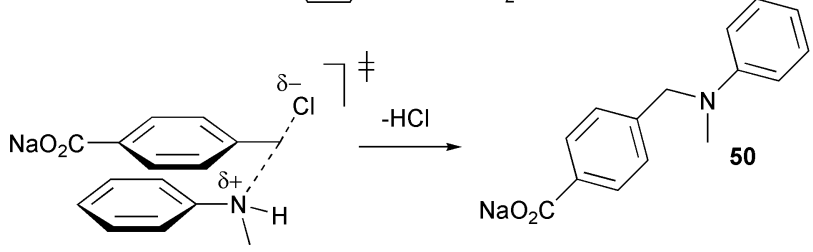

Scheme 7 Different geometries of the activated complexes of a set of $\mathrm{S}_{\mathrm{N}} 2$ reactions in aqueous solution as inferred from the influence of organic cosolvents on reactivity. 


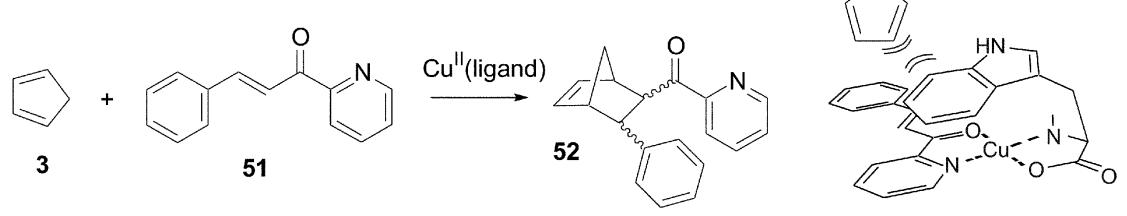

Scheme 8 An enantioselective Lewis-acid catalysed reaction in water. The tentative structure of the substrate-catalyst complex shows how stacking of aromatic rings shields one face of the substrate from approach by the diene. Hydrophobic interactions are thought to stabilise the stacked arrangement. $^{56}$

approach of the diene. The enantiomeric excess was found to be larger in water than in organic solvents, in line with the notion that HI favour the stacking of aromatic rings. Since the stacking of aromatic units is a common motif in enantioselective catalysis, the use of HI to strengthen stacked arrangements has considerable potential of enhancing enantioselective catalysis.

\section{Outlook}

We have summarised how reaction kinetics can be used to study the HI that occur in short-lived encounter complexes in aqueous solution. At room temperature HI between the relatively small nonpolar parts of molecules in these encounter complexes are entropy driven, also when they are in the proximity of functional groups that can engage in hydrogen-bonding interactions with water such as esters and amides. More surprisingly, also some carbohydrate cosolutes have been found to behave as if they were hydrophobic molecules, suggesting the existence of solvent-separated HI.

The influence of HI can be harnessed to speed up organic reactions in water. However, thus far $\mathrm{HI}$ have only in exceptional cases proven to be dominant in the solvent effects exerted by water. In most cases polarity and hydrogen bonding changes upon going from organic solvents to water have a stronger influence on the rate of the reaction. Nevertheless, an additional one to two orders of magnitude rate enhancement due to HI can still be useful. This applies in particular to cases where the selectivity of the reaction is important, in which case HI can selectively favour the reaction to form one isomeric compound over another.

We have reviewed a number of reactions, for which $\mathrm{HI}$ induce significant rate enhancements, including the Diels-Alder reaction, the 1,3-dipolar cycloaddition, and the Claisen rearrangement. The careful study of the effect of water on these reactions has allowed us to recognise the features that may help in identifying other reactions with a potential of being accelerated by water through $\mathrm{HI}$ : acceleration is expected for those reactions for which the total of solvent-exposed nonpolar surface area is reduced during the activation process. This can be either due to the reaction bringing nonpolar surfaces in close contact ${ }^{57}$ or due to an increase in the polarity of the reactant(s) during the reaction.

Despite possible solubility constraints, there are quite a number of reasons for selecting water as the medium for particular organic transformations. We contend that future work will show how rates, yields, and selectivities can benefit from a reaction design that takes advantage of the unique characteristics of water. In this respect, the use of HI constitutes both a challenge and a perspective.

\section{Acknowledgements}

J. E. is much indebted to his coworkers mentioned in the references for their enthusiasm and important contributions. Particular thanks are due to Professor M. J. Blandamer for many years of fruitful cooperation and to Dr. N. J. Buurma, whose graduate research is discussed in the first part of this Perspective.

\section{References}

1 For reviews, see: (a) W. Blokzijl and J. B. F. N. Engberts, Angew Chem., Int. Ed. Engl., 1993, 32, 1545 (Angew. Chem., 1993, 105, 1610); (b) N. T. Southall, K. A. Dill and A. D. J. Haymet, J. Phys. Chem. B, 2002, 106, 521; (c) L. R. Pratt and A. Pohorille, Chem. Rev., 2002, 102, 2671; (d) R. Schmid, Monatsh. Chem., 2001, 132, 1295.

2 (a) H. S. Frank and M. W. Evans, J. Chem. Phys., 1945, 13, 507; (b) M. H. Abraham, J. Am. Chem. Soc., 1982, 104, 2085.

3 G. Graziano, J. Chem. Soc., Faraday Trans., 1998, 94, 3345.

4 For a review, see: V. V. Yaminsky and E. A. Vogler, Curr. Opinion Coll. Interf. Sci., 2001, 6, 342.

5 J. R. Haak and J. B. F. N. Engberts, J. Am. Chem. Soc., 1986, 108, 1705 .

6 Y.-K. Cheng and P. J. Rossky, Nature, 1998, 392, 696.

7 M. J. Blandamer, J. B. F. N. Engberts, manuscript in preparation.

8 For some brief reviews, see: $(a)$ J. B. F. N. Engberts and M. J. Blandamer, J. Phys. Org. Chem., 1998, 11, 841; (b) J. B. F. N. Engberts and M. J. Blandamer, Chem. Commun., 2001, 1701; (c) M. J. Blandamer, J. Burges, J. B. F. N. Engberts and F. Sanchez, Faraday Discuss., 1988, 85, 309.

9 M. J. Blandamer, J. Burgess, H. J. Cowles, A. J. de Young, J. B. F. N. Engberts, S. A. Galema, S. J. Hill and I. M. Horn, J. Chem. Soc., Chem. Commun., 1988, 1141.

10 (a) T. H. Fife and D. M. McMahon, J. Am. Chem. Soc., 1969, 91, 7481; (b) J. F. J. Engbersen and J. B. F. N. Engberts, J. Am. Chem. Soc., 1975, 97, 1563; (c) W. Karzijn and J. B. F. N. Engberts, Tetrahedron Lett., 1978, 1787.

11 (a) M. F. Lensink, J. Mavri and H. J. C. Berendsen, J. Comput. Chem., 1999, 20, 886; (b) T. Rispens, M. F. Lensink, H. J. C. Berendsen and J. B. F. N. Engberts, J. Phys. Chem. B, to be submitted.

12 (a) W. Blokzijl, J. B. F. N. Engberts and M. J. Blandamer, J. Am. Chem. Soc., 1990, 112, 1197; (b) H. Benak, J. B. F. N. Engberts and M. J. Blandamer, J. Chem. Soc., Perkin Trans. 2, 1992, 2035.

13 W. Blokzijl, J. B. F. N. Engberts, J. Jager and M. J. Blandamer, J. Phys. Chem., 1987, 91, 6022.

14 (a) N. J. Buurma, L. Pastorello, M. J. Blandamer and J. B. F. N. Engberts, J. Am. Chem. Soc., 2001, 123, 11848; (b) N. J. Buurma, Ph.D. Thesis, University of Groningen, The Netherlands, 2003.

15 (a) J. B. F. N. Engberts, Water Compr. Treatise, 1972-1982, 1979, 6, ch. 4; (b) R. Lumry and S. Rajender, Biopolymers, 1970, 9, 1125.

16 For a detailed study of the hydration thermodynamics of aliphatic alcohols, see: G. Graziano, Phys. Chem. Chem. Phys., 1999, 1, 3567.

17 (a) W. H. Noordman, W. Blokzijl, J. B. F. N. Engberts and M. J. Blandamer, J. Org. Chem., 1993, 58, 7111; (b) P. Hol, L. Streefland, M. J. Blandamer and J. B. F. N. Engberts, J. Chem. Soc., Perkin Trans. 2, 1997, 485.

18 J. J. Savage and R. H. Wood, J. Solution Chem., 1976, 10, 733.

19 G. Graziano and G. Barone, J. Am. Chem. Soc., 1996, 118, 1831.

20 (a) S. A. Galema, M. J. Blandamer and J. B. F. N. Engberts, J. Org. Chem., 1992, 57, 1995; (b) For a supporting MD simulation, see: S. A. Galema, E. Howard, J. B. F. N. Engberts and J. R. Grigera, Carbohydr. Res., 1994, 265, 215.

21 For reviews, see: (a) A. Lubineau, J. Auge and Y. Queneau, Synthesis, 1994, 741; (b) C. Li, Chem. Rev., 1993, 93, 2023; (c) J. B. F. N. Engberts, B. L. Feringa, E. Keller and S. Otto, Recl. Trav. Chim. Pays-Bas, 1996, 115, 457; (d) C. Li and T.-H. Chan, Organic Reactions in Aqueous Media, Wiley, New York, 1997; (e) P. A. Grieco, Organic Synthesis in Water, Blacky Academic and Professional, London, 1998; $(f)$ K. Manabe and S. Kobayashi, Chem. Eur. J., 2002, 8, 4095; (g) U. M. Lindström, Chem. Rev., 2002, 102, 2751.

22 For a review on Diels-Alder reactions in water, see: S. Otto and J. B. F. N. Engberts, Pure Appl. Chem., 2000, 72, 1365.

23 R. Breslow and D. Rideout, J. Am. Chem. Soc., 1980, 102, 7816.

24 C. Reichardt, Solvents and Solvent Effects in Organic Chemistry, $2^{\text {nd }}$ ed., VCH, Weinheim, 1988 
25 G. Desimoni, G. Faita, P. P. Righetti and L. Toma, Tetrahedron 1990, 46, 7951.

26 J. W. Wijnen and J. B. F. N. Engberts, Liebigs Ann./Recl., 1997, 1085.

27 W. Blokzijl, Ph. D. Thesis, University of Groningen, The Netherlands, 1991.

28 A. Meijer, S. Otto and J. B. F. N. Engberts, J. Org. Chem., 1998, 63, 8989.

29 I. Hunt and C. D. Johnson, J. Chem. Soc., Perkin Trans. 2, 1991, 1051.

30 A. Lubineau, H. Bienaymé, Y. Queneau and M. Scherrmann, New J. Chem., 1994, 18, 279.

31 (a) J. F. Blake and W. L. Jorgensen, J. Am. Chem. Soc., 1991, 113, 7430; (b) J. F. Blake, L. D. Lim and W. L. Jorgensen, J. Org. Chem., 1994, 59, 803; (c) T. R. Furlani and J. Gao, J. Org. Chem., 1996, 61, 5492; (d) Y. Pak and G. A. Voth, J. Phys. Chem. A, 1999, 103, 925; (e) Y. Harano, H. Sato and F. Hirata, Chem. Phys., 2000, 258, 151; ( $f$ ) S. Kong and J. D. Evanseck, J. Am. Chem. Soc., 2000, 122 10418; ( $g$ ) J. Chandrasekhar, S. Shariffskul and W. L. Jorgensen, J. Phys. Chem. B., 2002, 106, 8078.

32 D. van Mersbergen, J. W. Wijnen and J. B. F. N. Engberts, J. Org. Chem., 1998, 63, 8801

33 K. J. Dignam, A. F. Hegarty and P. L Quain, J. Org. Chem., 1978, 43, 388.

34 Y. Inoue, K. Araki and S. Shiraishi, Bull. Chem. Soc. Jpn., 1991, 64, 3079 .

35 (a) M. R. Gholami and A. H. Yangjeh, J. Chem. Res. Synop., 1999, 226; (b) M. R. Gholami and A. H. Yangjeh, Int. J. Chem. Kinet., 2000, 32, 431

36 M. P. Repasky and W. L. Jorgensen, Faraday Discuss., 1998, 110, 379.

37 For some excellent reviews, see: (a) B. Ganem, Angew. Chem., Int. Ed. Engl., 1996, 35, 937 (Angew. Chem., 1996, 108, 1014); (b) J. J. Gajewski, Acc. Chem. Res., 1997, 30, 219.

38 E. Brandes, P. A. Grieco and J. J. Gajewski, J. Org. Chem., 1989, 54, 515.

39 J. J. Gajewski, J. Org. Chem., 1992, 57, 5500

40 (a) S. Otto, W. Blokzijl and J. B. F. N. Engberts, J. Org. Chem., 1994, 59, 5372; (b) J. B. F. N. Engberts, Pure Appl. Chem., 1995, 67, 823.

41 (a) D. L. Severance and W. L. Jorgensen, J. Am. Chem. Soc., 1992, 114, 10966; (b) C. J. Cramer and D. G. Truhlar, J. Am. Chem. Soc., 1992, 114, 8794; (c) J. Gao, J. Am. Chem. Soc., 1994, 116, 1563 (d) M. M. Davidson, I. H. Hillier, R. J. Hall and N. A. Burton, J. Am. Chem. Soc., 1994, 116, 9294; (e) M. M. Davidson and
I. H. Hillier, J. Phys. Chem., 1995, 99, 6748; A. Sehgal, L. Shao and J. L. Gao, J. Am. Chem. Soc., 1995, 117, 11337; $(f)$ J. M. Guest, J. S. Craw, M. A. Vincent and I. H. Hillier, J. Chem. Soc., Perkin Trans. 2, 1997, 71

42 M. H. Abraham, P. L. Grellier, A. Nasehzadeh and R. A. C. Walker, J. Chem. Soc., Perkin Trans. 2, 1988, 1717.

43 (a) A. Lubineau, J. Org. Chem., 1986, 51, 2142; (b) A. Lubineau and E. Meyer, Tetrahedron, 1988, 44, 6065 .

44 T.-P. Loh, L.-C. Feng and L.-L. Wei, Tetrahedron, 2000, 56, 7309

45 H. Yorimitsu, T. Nakamura, H. Shinokubo, K. Oshima, K. Omoto and H. Fujimoto, J. Am. Chem. Soc., 2000, 122, 11041.

46 X.-K. Jiang, W.-Q. Fan and Y.-Z. Hui, J. Am. Chem. Soc., 1984, 106, 7202.

47 X.-K. Jiang, Y.-Z. Hui and Z.-X. Fei, J. Chem. Soc., Chem. Commun., 1988, 689.

48 W.-Q. Fan and X.-K. Jiang, J. Am. Chem. Soc., 1985, 107, 7680.

49 R. Breslow, Acc. Chem. Res., 1991, 24, 159.

50 (a) E. T. Kool and R. Breslow, J. Am. Chem. Soc., 1988, 110, 1596; (b) R. Breslow and R. V. Conners, J. Am. Chem. Soc., 1995, 117, 6601 .

51 (a) R. Breslow and Z. N. Zhu, J. Am. Chem. Soc., 1995, 117, 9923; (b) R. Breslow, R. Conners and Z. N. Zhu, Pure Appl. Chem., 1996, 68, 1527; (c) R. Breslow, K. Groves and M. U. Mayer, Pure Appl. Chem., 1998, 70, 1933.

52 (a) R. Breslow and R. Conners, J. Am. Chem. Soc., 1996, 118, 6323; (b) R. Breslow, K. Groves and M. U. Mayer, Org. Lett., 1999, 1, 117; (c) R. Breslow, K. Groves and M. U. Mayer, J. Am. Chem. Soc., $2002, \mathbf{1 2 4}, 3622$.

53 T. Asano and W. J. LeNoble, Chem. Rev., 1978, 78, 407.

54 (a) R. Breslow, U. Maitra and D. Rideout, Tetrahedron Lett., 1983, 24, 1901; (b) R. Breslow and U. Maitra, Tetrahedron Lett., 1984, 25, 1239.

55 P. S. Pandey and I. K. Pandey, Tetrahedron Lett., 1997, 38, 7237.

56 (a) S. Otto, G. Boccaletti and J. B. F. N. Engberts, J. Am. Chem. Soc., 1998, 120, 4238; (b) S. Otto and J. B. F. N. Engberts, J. Am. Chem. Soc., 1999, 121, 6798.

57 A frequently encountered argument in the literature states that reactions with a negative volume of activation featuring nonpolar reactants will be accelerated through HI. However, it is not so much the reduction in volume as the reduction in surface area that is in contact with water that matters, although in practice area and volume terms will usually be correlated.

58 R. N. Butler, A. G. Coyne, W. J. Cunningham and L. A. Burke, J. Chem. Soc., Perkin Trans. 2, 2002, 1807. 